\title{
Data in Forensic Phonetics from theory to practice
}

\author{
Chiara Meluzzi*, Sonia Cenceschi**, Alessandro Trivillini** \\ * University of Pavia; ** Digital forensic service, Department of Innovative Technologies, \\ University of Applied Sciences of Southern Switzerland (SUPSI) \\ chiara.meluzzi@unipv.it, sonia.cenceschi@supsi.ch, alessandro.trivilini@supsi.ch
}

\begin{abstract}
What are speech data? The question is not as trivial as it may seem: every day both theoretical and applied linguistic research come up against problems deriving from bad data management. This topic is particularly thorny in interdisciplinary approaches such as the speech forensics analysis, whereby the recorded speech can be exploited as legal clues, with important repercussions on public security and citizens' rights. The datum does not exist in nature, being it a consequence of the human analysis of a given phenomenon. In fact, data extraction is based on explicit and implicit theories implemented by the researcher within the application of specific frameworks. Researchers and professionals working on empiric data should be more aware of these underlined processes in order to avoid data misuse and, indeed, maximize results. In this paper, we will briefly address the issue of the speech data epistemology with a particular focus on the interdisciplinary approach required in forensics (e.g. between linguistics and engineering), by discussing examples from Italian real cases. Moreover, it must be clarified what different experts (e.g., lawyers vs. linguists) mean as datum in forensic research.
\end{abstract}

Keywords: forensic phonetics, speech data, data analysis, noise audio evaluation, bad data problem

\section{Introduction ${ }^{1}$}

The main aim of this paper is to provide a concise reflection on what is considered a datum in forensic linguistics (cf. Olsson 2009, 2018), and in particular in forensic phonetics (cf. Hollien 2012) and how different disciplines and methodologies could look at the same phenomenon from different yet complementary perspectives. The recognition of how different methodologies could influence the way a phenomenon becomes a datum is, indeed, particular relevant in a forensic setting. Therefore, by providing some theoretical considerations on the 
notion of datum, we will offer some practical applications in forensic phonetics, which will lead to some suggestions for improving the dialogue between experts with different backgrounds and the law institutions.

The core point to be highlighted is that data are not a natural-occurring experience, but rather theory-oriented filtered from reality (Popper 1962[2014]). It means that the way a phenomenon acquires the status of datum depends on both the theory and the research questions. As a consequence, different disciplines will categorize the same phenomenon into different data. For instance, we can consider a simple case of a naturally-occurring conversation on the weather between two strangers at the bus station. From the same recording, in phonetics we will extract vowels' formants, or consonants places of articulation in order to test inter-speaker variation. In discourse analysis, we will consider the dialogical structure of the conversation, whereas from a pragmatic point of view we might be interested in considering the content of the dialogue such as the reference to a shared knowledge (e.g., talking about weather is a common topic between strangers). Although only within linguistics, we can see that different sub-disciplines will look at the same phenomenon from different perspectives, and therefore consider different elements as data: for a phonetician it will be the phones as they are pronounced, but these elements will not be relevant for a pragmatist, who instead may wish to consider (and label) the topic of the conversation or the use of formulaic language.

Forensic linguistics constantly faces this issue: this field of research involves the analysis of language for forensic purposes, at both a textual and a speech level (cf. Olsson 2009, 2018 for an introduction to the discipline). Forensic linguistics represent an interface between language and the law (cf. Larner 2015), thus having a strong interdisciplinary nature combining both different linguistic competences (from discourse analysis to acoustic phonetics), but also needing different experts to dialogue on the same phenomena. For this reason, there must be accuracy and transparency about how data have been acquired, catalogued and examined. Even though this could be considered as a general good practice in applied linguistics and, more generally, in experimental sciences, this is not always the case when working in forensics, since data acquisition and management is often treated by different experts (lawyers, officers, sound engineers) before the proper linguistic analysis. In this respect, we hope that by being conscious of the epistemological difference between phenomena and data, it will be possible to avoid many misunderstandings among experts, and also between the expert, the public, and law enforcement officers for which forensic linguists often worked for. 
The paper comprises a general introduction to data theory followed by its application to the forensics field. Several examples of real cases are thus placed alongside the theory of data to draw an overview aiming at clarifying the complexity and multi-disciplinarity of forensic phonetics.

\section{Epistemology of data in linguistics: a brief remark}

Within linguistics itself, data could be differently acquired and used according to the research field (e.g., generative vs. functional approaches), and the research question behind the specific work. The issue of the relationship between theory and data has been at the core of Popper's (1962)[2014] work, and from this it has been further developed within the philosophy of language. Moving from a previous reflection by Aroux (1998), Iannàccaro (2000) proposed a first classification of the functions of linguistic data based on the theory behind their acquisition. A first basic distinction is introduced between data collection and data invention, the first being the most common procedure in applied linguistics, whereas the second being more typical of generative works based on evaluations and testing of linguistic forms. Since forensic linguistics could be considered part of the broad category of applied linguistics, we will focus only on the procedures beneath data collection.

Three modalities of data collection are highlighted by Iannàccaro (2000): desk research (grammars, dictionaries), laboratory data, and fieldwork research. Whatever the case, each modality reflects both explicit and implicit theory of the researcher on its own research, on its purposes and what he/she wants to demonstrate with this data. In fieldwork research, researcher's theories sum up with informant's theories: indeed, ethnolinguistic and dialectological research has demonstrated that speakers tend to be more or less positive towards the research itself if they perceive it as directly relatable to something valuable for them. In Italian dialectology there are many examples of speakers' influence over the data provided: this has been noticed since the works of Bottiglioni (1935), but see also a thorough comment on Iannàccaro (2002). The influence of speakers' theories on what language and research are (or should be), have been at the core of sociolinguistic research since its very beginning, with the famous Labovian observer's paradox (cf. Labov 1972). Furthermore, a specific field of research has developed from these anecdotes: nowadays, perceptual dialectology and folk linguistics (see Preston 2011) are now distinguished research paradigm for the studying of language perception and attitudes, with their results often used in sociolinguistic analysis. 
After data collection, the transcription also represents an important correlate of implicit and explicit theory adopted by the researcher(s). Ochs (1979) clearly pointed out how the decision between standard orthography vs. phonetic/phonological transcription influence the understanding of the recording or dialogical behaviour: on one hand, orthography leads to a major focus on the content of the recordings, whereas phonetic transcription focuses more on the shape of the content. Metaphorically speaking, we can address this issue as the "sieveproblem" (Iannàccaro \& Meluzzi, 2014): if your tights are too wide, the risk is to miss something important; conversely, though, if you prefer a tight transcription (or annotation) you risk hyper-categorization, making it impossible to ultimately categorize your linguistic data into parameters for analysis.

Therefore, when addressing linguistic data it is important to keep in mind that there are always implicit and explicit theories of what language is and how it should be represented and analyzed. If this issue should be at the core of every linguistic analysis, it has not yet been addressed for "border" disciplines like forensic linguistics. In this case the situation is far more problematic, since the researchers' needs and theories have to consider (and, often, argue with) the non-specialists requiring a linguistic report. The question to be answered in this case is: how do I provide a transcription which is at the same time accurate with respect to the phenomenon under analysis (researcher's implicit/explicit theory) and comprehensible for the attorney who needs this report (informant's implicit/explicit theories)? Although there is not a unique solution, it will be good for both sides to keep in mind the issue beneath theory-data relationship.

\subsection{The sample size and the "bad data" problem}

Deeply related to the aforementioned problematic relationship between data collection and the implicit/explicit theory beneath it, sample size is also a problem to be considered. This issue has been differently addressed in various linguistic fields, in particular by corpus linguistics and sociolinguistics. Indeed, it is quite famously the so-called "bad data problem" firstly formulated by Labov (1972, p. 98): 'bad' here as to be intended as "fragmentary, corrupted, or many times removed from the actual productions of native speakers". Though Labov postulated this notion for historical linguistic research, it is evident it could be easily adapted to every researcher working with data collected directly from fieldwork and not from a controlled environment (e.g., laboratories). Recently, historical sociolinguistics has changed this view on the "bad data problem" by assuming the possibility to make the best use of the bad data (cf. 
Nevalainen 1999). This means being aware of the limitation of the sample size both in terms of quantity and of quality of the data.

The issue of "bad data" should also be carefully addressed in forensic linguistics, in particular while working with phonetic data, with a further limitation. Basically, in linguistic research you are almost often responsible for selecting your own data sample (although some limitations exist), either because you directly collect your oral or written data from reality, or because you select a subsample from a previous collected corpora. However, working in forensics means a change of paradigm: in many cases, data is provided to the linguist by a lawyer or a police officer with a very specific request on what these data are needed for. In many cases, at least according to Italian juridical system, the expert could not access further information regarding how the data have been collected, stored and used. It should be easy to understand now that this poses a serious threat to the number of possible false leads occurring during a linguistic evaluation for forensic purposes, since there is potentially zero awareness of the explicit and implicit theories beneath both data collection and the question addressed by the non-linguist specialist. We will address these issues in the remaining sections of this paper.

\section{Forensic linguistics and its actors}

Forensic linguistics is a developing discipline, with a growing demand of expertise from different organisms (e.g., lawyers, tribunals, as well as forensic journalism). The linguistic competences needed in forensics span from textual analysis to acoustic, also taking into account corpus linguistics and discourse analysis (Conrad, 2002). Although these competences would require professional figures with a background in linguistics, sound engineering, and related disciplines, too many case reports (especially in public settings such as tribunals) are demanded by public officers or other semi-professional figures without a specific scientific background. Too often in Italy professionals are not prepared to deal with the specific demands and requirements of forensic analysis (see the famous cases discussed in Olsson 2009), and a professional catalogue of experts still does not exist.

Conversely, judges, lawyers and law enforcement officers need to be guided in order to make the best use of the audio recording. However, the lack of specific regulations is entrusted to subjective responsibility. Although here we will focus on the Italian case, these issues are not limited to this specific country but are far too common in many other countries as well (French, 1994, Coulthard \& Johnson, 2010). 
In this respect, a central issue is the construction and spread of a common consciousness regarding the definition of data and its variability with context and purposes. Indeed, a divergence on these focal points leads to misunderstandings between the various professionals in security. Knowing the data means not only knowing how to extract it, but also be aware of its potential and correct treatments. In short, human voice experts and legal professionals must find a common vocabulary.

\section{Data in forensic phonetics}

Many types of phonetic data exist in forensics, and their nature mainly depends on various internal and external factors:

- Purpose of the investigation

- Quality of the speech

- Compression format

- Amount of available speech data

- Chain of custody

The purpose is dictated by the type of legal proceeding or investigation. Audio data may contain several different pieces of information, but the analysis takes on a different declination according to the specific case, the context, and the process behind it. Three practical examples widespread in real work-cases are reported in Table 1.

\begin{tabular}{|l|l|l|l|}
\hline PRACTICAL CASE & \multicolumn{1}{|c|}{ PURPOSE } & \multicolumn{1}{|c|}{$\begin{array}{c}\text { DATA } \\
\text { TYPOLOGIES }\end{array}$} & $\begin{array}{r}\text { POSSIBLE } \\
\text { ANALYSIS }\end{array}$ \\
\hline $\begin{array}{l}\text { Transcription of noisy } \\
\text { audio }\end{array}$ & $\begin{array}{l}\text { Contents } \\
\text { understanding }\end{array}$ & Linguistic & $\begin{array}{l}\text { Perceptive } \\
\text { Phonetic }\end{array}$ \\
\hline $\begin{array}{l}\text { Identify a person } \\
\text { guilty of crime }\end{array}$ & $\begin{array}{l}\text { Comparison of } \\
\text { unknown and } \\
\text { known voice/s }\end{array}$ & Audio & $\begin{array}{l}\text { Perceptive } \\
\text { Phonetic } \\
\text { Prosodic }\end{array}$ \\
\hline Speaker's profiling & $\begin{array}{l}\text { Detecting age } \\
\text { range, sex or }\end{array}$ & Audio & Linguistic \\
\hline
\end{tabular}




\begin{tabular}{|l|l|l|l|}
\hline & $\begin{array}{l}\text { geographical } \\
\text { origin }\end{array}$ & & $\begin{array}{l}\text { Prosodic } \\
\text { Language use } \\
\text { Spectrographic }\end{array}$ \\
\hline
\end{tabular}

Table 1: Examples of phonetic analysis for forensic purposes.

As for the different types of analysis, perceptive ones are fundamentally based on perceptual tests conducted by trained or untrained phoneticians (or both), as recommended in literature (Hollien, 2012). In forensics as well as in other disciplines the difference between phonetic and phonological analysis concerns the segmental vs. suprasegmental level. Indeed, phonetic analysis deals with the segmental level, by considering the individual snips of the speech (vowels, consonants, silences, etc.), their spectral features, and their mutual relationship; prosodic analysis considers suprasegmental factors, like the temporal behaviour of local features (intonation, amplitude envelope, etc.).

Spectrographic analysis is a more specific phonetic analysis concerning the extraction of spectral features such as MFCC, Centroid, Spectral slope, among many other factors, and machine-computer approaches based on them (cf. for a linguistic overview, Harrington, 2013). Finally, with the label "linguistic analysis" go to other levels of the study of language for forensic purposes, like textual and dialogical structure, grammar, terminology, and pragmatics.

Each one of the previous analyses may or may not be carried out depending on the quality of the recording. Most forensic audio is recorded in difficult conditions from both an environmental and a technological point of view, and in these extremely variable conditions, the signal-to-noise ratio may not be sufficient to carry out an investigation. Therefore, the expert must refuse to work on the audio if the signal is too degraded or noisy, and the intellectual and scientific honesty comes into play. High quality speech is usually considered to have a SNR equal to 55-60 dB (Barinov, 2010), and although there are no rules defined in Italy regarding the threshold, $60 \mathrm{~dB}$ should be the minimum recommended value. Thus, the quality of speech could affect the possibilities to carry out a phonetic analysis, since it prevents acquiring useful data.

Moreover, forensic recordings are often saved in compressed formats, with spectral thresholds below $7000 \mathrm{~Hz}$ and minimal sampling. This poor quality, coupled with the low SNR problem, 
also leads to difficulties in case-work. As an extreme example, we could make a simple analogy: removing background noise from an extremely compressed format is like restoring a painting ruined by smog and finding that there is no colour left under the dirt: only the "poor external shape" remains. It is therefore easy to understand how a less compressed data is richer and more desirable in forensics.

Furthermore, the amount of available audio is often very limited (Broeders, 2001). For example, a long environmental recording may contain only a few interesting instances. A few sentences of dialogue between two speakers is not enough for any speakers' comparison, and may be limited even for a socio-phonetic analysis or a psychoacoustics test, due to the poor quality of the recording. Unfortunately, each case is different, and the expert, law enforcement officers, and legal parties have to face new technical challenges every time.

The chain of custody (Maher, 2010; AES27, 1996) is the documentation that records the sequence of custody, control, transfer, and analysis of the recording. Identifying the chain provides information about whether or not this evidence has been copied or modified, but also guarantees to work on meaningful and truthful speech. The major issues in audio forensics is that too many times the expert receives an audio without history, whose passages and compressions can be intuited but not proven, often also leading to the dispute of the expert reports.

\subsection{Misunderstandings in the treatment of forensic data}

In light of what has been said, it is clear how the data itself, once identified, is usable in a different way depending on the case. We report now two concrete examples of leaks in communication between linguistics/sound analysis experts (Van Swol \& Sniezek, 2005), and the legal/security applicative field. These examples do not apply to a specific case, but represent generalization from many different cases discussed in literature (e.g., Olsson, 2009) and occurred also to the authors of this paper.

The first example is typical of the criminal sector: a judge asks the linguistic expert to compare two voices (an unknown and a known speaker) contained in two different recordings. These recordings differ from each other on various features: the recording modality, the digital format, the background noise, the low quality of speech, etc. The judge thinks that the datum here is the concept of "voice", considering the linguistic content and the audio components as a whole. What is expected by the expert is an unequivocal answer (Yes/No), and he/she 
delegates all technical choices to the expert. Conversely, the expert considers as data only the (usable) acoustic components of the audio, knowing that not all the recording could be used to compare the two voices due to the noise. The expert also knows that voice comparison does not lead to categorical answers, but that there will be only some segmental or suprasegmental features that help differentiating the known vs. unknown voices. Thus, in the majority of the cases the expert can't provide an unequivocal Yes-or-No answer (if he/she has a sufficient work ethic), but he/she will provide a list of differences and similarities of the two recordings and his/her opinion on the identity of the two speakers.

In this first example, what constitutes a datum is not the same for the two parties (i.e., the judge and the linguistic expert), and this implies different expectations depending on the role of the two parties in the investigation process. In the end, one party must surrender to the other: quite often, the expert is asked to simplify the results, ignoring a necessary scientific uncertainty at the expense of the comprehension of the non-experts in need for a straightforward answer to a specific question (Is it the same voice?). Knowing the data means knowing its possible use, while leads to incorrect expectations or analysis.

A second example is the case of a lawyer who would like to know if a recording contains female or male voices. However, due to the poor quality of the recordings or other environmental and instrumental factors, the expert can isolate just a few human whispers without harmonic components from the audio. The data for the lawyer is the speaker's presence, also because he/she listened to the audio and perceived a female voice. However, for the expert the data is represented by the sound component of the single temporal clipping. The phonetic forensic expert should know that the analysis for gender detection must be at phonetic level, but that the whispers are assimilated to disguised speech (Pooja \& Vyas, 2015). Furthermore, the presence of a low pitch and/or harmonic components in whispers offer too little information to reach any definitive conclusion (Bartle \& Dellwo, 2015).

The expert will be justified in refusing to provide an opinion, explaining the technical reasons. Once again, the lawyer may not wish to read a technical report, considering the data analyzed by the expert as irrelevant, while the "real datum" should be the voice. The lawyer may, thus, search for a new expert, who will provide in the end a less technical or non-technical report, basing only on subjective and biased perceptual preconceptions (e.g., knowing or maybe wishing the presence of a female speaker in the recording). 


\section{Discussion}

The notion of what constitutes a useful datum has not yet been fully considered in applied linguistic research. However, real case works in forensics are demonstrating the importance of a theoretic reflection on how data are categorized by different disciplines and experts, and also on what we expect from the data in applied analysis. Since in dealing with data there are always implicit and explicit theories of the researcher to be accounted for, in case of interdisciplinary works it should make explicit what part of the phenomena under investigation constitute a datum for the different experts involved.

As a matter of fact, forensic phonetics (and linguistics more generally) must be seen as an interdisciplinary field of research, at the intersection between applied linguistics, phonetics, and sound engineering. Indeed, signal analysis and knowledge of the fundamentals of textual, phonetic and prosodic analysis can no longer be used separately by different experts, completely ignoring each other's fields. In this paper, we limited our examples to phonetics, a field in which it is quite easy to need collaborations with psychiatrists, computer engineers, etc. Obviously, we believe that the same considerations could applied for text-based data, which represent one of the main interface between the study of language (mainly from the point of view of discourse analysis) and the law (for a recent overview, see Orletti \& Mariottini, 2017).

The dialogue between the different involved experts is necessary, and it is not always easy to achieve. Furthermore, one should not forget that in forensics it is also mandatory to dialogue with the most important consultants, that is legal and security officers. Each collaboration should be based on a common and shared vocabulary to avoid misunderstandings. However, sometimes the very concept of what is a datum is not straightforward. As it has also being very recently pointed out by Heydon (2019), in forensic settings data are provided to the experts by police or lawyers, and are usually quite scarce with respect of linguistic variation, thus resulting in biased dataset. Furthermore, as we have highlighted in this paper, data are not the same for the different experts because it changes the point of view of the analysis, but acquiring awareness on mutual theories is certainly an excellent way to work together.

In this respect, there is a need of improving the dialogue between experts and non-experts, especially in Italy. In the closing chapter of her ground-breaking book, Hollien (1990) already offered some comments on ethics and responsibilities of both the experts and the lawyers or officers that may want to ask for the expert's opinions and use their testimony in court. For the 
expert, it is obvious that a knowledge of linguistics (and, in our case, in particular phonetics and phonology) of the target language (the language of the sample to be judged) is essential, together with technical skills on hardware and software equipment, digital audio restoration, and a background on sensitive data protection regulations. Furthermore, the so-called expert should also be aware of the specific forensic settings in his/her country, on how his/her reports will be used and on how provide an effective testimony in the courtroom (cf. Hollien, 1990, p. 334). Furthermore, the expert's work ethic should encourage to be plainly honest on the possibility of providing a fair report with corrupted data (e.g. very noisy recordings) and on the reliability of his/her analysis in light of the more recent phonetic theories. For the non-experts (judges, law enforcement officers or lawyers), a basic knowledge of the same linguistic and engineering principles of speech sound analysis is also essential. This would allow them to defend from false-experts (Fraser, 2018) or "rogue-experts", but also to define the data, and know what can be scientifically obtained from it. In fact, this different epistemological status of the "data" is reflected in the way they are treated, but also in the research questions and empirical possibilities that derive from these data (Cenceschi et al., 2019).

\section{Conclusions}

In this paper, we have discussed how in forensic phonetics is sometimes difficult to reach a good collaborations between all the experts and the parts involved in the process, since there is a general lack of consensus of what are the data we are working with. Theoretically speaking, it is important to spread knowledge about how data differ from actual phenomena, and that behind all categorization there are always implicit and explicit theories to take into account. By ignoring these issues, the risk will arise of lack of communications between the parts, leading to incomprehensible or unusable reports, or, even worse, by falsifying the results provided by the experts if not directly and unequivocally related to the (very practical) research question.

The solution to the listed issues on data is not univocal and it must be based on a coherence of position on the part of the concerned scientists. First of all, inviting the experts to collaborate between them, and secondly continuing with the exhausting awareness work, above all through the national scientific associations. The single expert must surely insist on an active collaboration and mutual exchange with the police and all the forces involved, without closing in on its technological castle but rather working on the scientific communication of methodologies and results. For example, some case-work shows how the collaboration between 
phoneticians and law enforcement officers during preliminary investigations (literally sitting side by side with headphones) can be extremely productive. However, these examples have not yet been published officially, and there is also a lack of official guidelines or an association of phonetic experts for lawyers and judges to refer to.

In conclusion, while the investigator knows the facts, the phonetists knows the speech signal: the two crossed skills mitigate errors and promote scientific understanding. In our experience a case successfully completed promotes positive "word of mouth" among the involved forces. Although it is always a good practice to be conscious about the limits of the data under investigations, those limits should not undermine the possibilities of good collaborations among experts and disciplines, thus making good use of bad data also in forensic phonetics.

\section{References}

AES27 (1996) AES Recommended practice for forensic purposes, Managing recorded audio materials intended for examination, New York, Audio Engineering Society.

Auroux, S. (1998) Le langage, la raison et les normes. Paris: Presses Universitaires de France.

Barinov, A. (2010) Voice samples recording and speech quality assessment for forensic and automatic speaker identification, Audio Engineering Society Convention 129. Audio Engineering Society.

Bartle, A., \& Dellwo, V. (2015) Auditory speaker discrimination by forensic phoneticians and naive listeners in voiced and whispered speech. International Journal of Speech, Language \& the Law, 22(2).

Bottiglioni, G. (1935) Etnografia apuana, Italia Dialettale XI: 153-170.

Broeders, T. (2001, July) Forensic speech and audio analysis Forensic Linguistics 1998-2001. In Proceedings 13th INTERPOL Forensic Science Symposium, Lyon, France D Vol. 2, pp. 54-84.

Cenceschi, S., Trivilini, A., \& Denicolà, S. (2019) The scientific disclosure of speech analysis in audio forensics: remarks from a practical application, XV AISV Conference, Arezzo, Italy.

Conrad, S. (2002) 4. Corpus linguistic approaches for discourse analysis. Annual review of applied linguistics, 22, 75.

Coulthard, M., \& Johnson, A. (Eds.) (2010) The Routledge handbook of forensic linguistics (pp. 473-486). London: Routledge. 
Fraser, H. (2018) Real forensic experts should pay more attention to the dangers posed by 'ad hoc experts', Australian Journal for Forensic Sciences, 50.2, 125-128.

French, P. (1994) An overview of forensic phonetics with particular reference to speaker identification. International Journal of Speech, Language and the Law, 1(2), 169-181.

Heydon, G. (2019) Researching Forensic Linguistics. Approaches and Applications. London: Routledge.

Hollien, H. (1990) The Acoustic of Crime. The new science of forensic phonetics. New York: Springer.

Hollien, H. (2012) About forensic phonetics. Linguistica, 52(1), $27-53$.

Iannàccaro, G. (2000) Per una semantica più puntuale del concetto di «dato linguistico»: un tentativo di sistematizzazione epistemologica, Quaderni di semantica, XXI.1: 51-79.

Iannàccaro, G. (2002) Il dialetto percepito, Alessandria: Edizioni dell'orso.

Iannàccaro, G. \& Meluzzi, C. (2014) Il concetto di "dato" in linguistica / The concept of "datum" in linguistics, PhD seminar, Pavia-Milano Bicocca, 16th May 2014.

Labov, W. (1972) Sociolinguistic Patterns, University of Pennsylvania Press.

Larner, S. (2015) From intellectual challenges to established corpus techniques: introduction to the special issue on forensic linguistics, Corpora, 10.2: 131-143.

Maher, R. C. (2010) Overview of audio forensics. In Intelligent Multimedia Analysis for Security Applications, pp. 127-144. Springer, Berlin, Heidelberg.

Nevalainen, T. (1999) Making the best use of 'bad' data: evidence for sociolinguistic variation in Early Modern English, Neuphilologische Mitteilungen, 499-533.

Ochs, E. (1979) Transcription as theory. In Schieffelin \& Ochs (eds.) Developmental pragmatics. New York: Academic Press.

Olsson, J. (2009) Wordcrime: Solving crime through forensic linguistics. London: A\&C Black.

Olsson, J. (2018) More Wordcrime: Solving crime with linguistics. London: Bloomsbury Publishing.

Orletti, F. \& Mariottini, L. (eds.) (2017) Forensic Communication in Theory and Practice. A study of Discourse Analysis and Transcription. Cambridge: Cambridge Scholars Publishing.

Pooja, A., \& Vyas, J. M. (2015) A Developmental Overview of Voice as a Steadfast Identification Technique. Journal of Forensic Research, 6(3), 1.

Popper, Karl (1962)[2014] Conjectures and refutations. The growth of scientific knowledge. London: Routledge. 
Preston, D. R. (2011). Perceptual dialectology: Nonlinguists' views of areal linguistics. London/Berlin: de Gruyter.

Van Swol, L. M., \& Sniezek, J. A. (2005). Factors affecting the acceptance of expert advice. British journal of social psychology, 44(3), 443-461.

\footnotetext{
${ }^{1}$ The article has been thought and written together by the three authors. However, for the requirements of the Italian Academy, Chiara Meluzzi should be considered responsible for sections 1, 2, 2.1, and 5; Sonia Cenceschi is responsible for sections 3, 4 and 4.1, whereas Alessandro Trivillini holds responsibility for section 6 .
} 